\title{
Assessing Healthcare Facilities Preparedness for Mass Fatalities Incident
}

\author{
Marisol Peña-Orellana ${ }^{1,2}$, Ralph Rivera-Gutiérrez ${ }^{1,2}$, Juan A. Gónzalez-Sánchez ${ }^{3}$, Nilsa Padilla-Elías ${ }^{1}$, \\ Heriberto Marín Centeno ${ }^{1,2}$, Héctor Alonso-Serra ${ }^{1}$, Liza Millán-Pérez ${ }^{1}$, Patricia Monserrate-Vázquez ${ }^{1}$ \\ ${ }^{1}$ Center for Public Health Preparedness, Graduate School of Public Health, Medical Sciences Campus, University of Puerto Rico, San \\ Juan, Puerto Rico; ${ }^{2}$ Department of Health Services Administration, Graduate School of Public Health, Medical Sciences Campus, \\ University of Puerto Rico, San Juan, Puerto Rico; ${ }^{3}$ Department of Emergency Medicine, School of Medicine, Medical Sciences \\ Campus, University of Puerto Rico, San Juan, Puerto Rico. \\ Email: marisol.pena@upr.edu
}

Received September $19^{\text {th }}, 2013$; revised October $17^{\text {th }}, 2013$; accepted November $15^{\text {th }}, 2013$

Copyright (C) 2013 Marisol Peña-Orellana et al. This is an open access article distributed under the Creative Commons Attribution License, which permits unrestricted use, distribution, and reproduction in any medium, provided the original work is properly cited.

\begin{abstract}
Background: Any healthcare facility must be prepared to handle a dramatic increase in deaths that can be produced by a catastrophic disaster. A mass fatality incident (MFI) will significantly increase the usual number of deaths that hospitals or forensic science services can manage on a daily basis. A survey was conducted to assess the hospital emergency department level of preparedness to deal with an MFI. Objective: To examine healthcare facilities level of preparedness for an MFI and morgue capacity. Methods: A total of 39 out of a sample of 44 hospitals participated in the study. Seven questionnaires were administered to explore: hospital general characteristics; emergency plans; equipment and infrastructure; collaborative agreements; personnel trainings; emergency communications; laboratory facilities; treatment protocols; security; and, epidemiologic surveillance. Results: Three-fourths (79.5\%) of the healthcare facilities reported having a morgue, their average storage capacity was of three bodies. More than two-thirds (66.7\%) of the institutions stated that they could not increase their morgue's capacity. Most installations without a morgue do not possess an agreement with any other institution for the management of bodies. Hospitals have a very limited number of body bags utilized for the handling and transport of bodies. Conclusion: Most of healthcare facilities have morgues, but there are limitations with the current capacity and the lack of resources to increase their capacity in case of a disaster. Management of an MFI must be part of every hospital's emergency plan, and must include collaborative agreements with forensic authorities, emergency management and public health agencies, and the community.
\end{abstract}

Keywords: Hospitals; Morgues; Mass Casualties; Mass Fatalities; Puerto Rico

\section{Introduction}

Disaster events, caused by natural hazards or manmade, can occur anywhere in the world at any time. Emergencies are not entirely predictable, but when these occur they can cause an immediate demand for public health resources and health care services [1-3]. The capabilities of the affected country can be compromised to the maximum exposing deficiencies at various levels of the disaster mitigation process. Most local governments are not adequately equipped to support preventive measures before the disaster's occurrence. In addition, government agencies have limited capacities to respond to disasters, basically due to budget constraints, and are often unable to provide the locations needed for temporary or perma- nent relocation sites for those whose homes and settlements were destroyed or severely damaged or to store large numbers of corpses [4-6]. Recent major disasters have yielded important evidence regarding how the number of mass casualties and fatalities can overwhelm the capacity of a country's public health and healthcare system to effectively respond to the emergency [7-10]. One of the most difficult aspects of a catastrophic disaster is related to the management of a large number of dead bodies, due to the processes involved in the recovery, identification, and disposal, as well as the effectiveness of disaster preparedness plans and communication between respective agencies and the affected population [11]. Morgan and colleagues [12] conducted a descriptive study to document how the dead were managed in 
Thailand, Indonesia and Sri Lanka, after the 2004 Indian Ocean Tsunami, which resulted in the death of 165,000 people. The researchers used participant observations from post-tsunami response teams, conducted semistructured interviews, and collected information from published and unpublished documents. Results from this study showed issues such as: the absence of refrigeration for preserving human remains soon after the disaster; the need to use other refrigeration methods, such as dry ice and the challenges this brought given that it did not provide enough cooling to stop decomposition; insufficient forensic personnel for identification; variability among the countries in dealing with corpses; rapid decomposition of corpses; and a lack of a national mass fatality plan.

In a research study conducted by Sahelangi and Novita [13], several challenges with dead bodies after the Indonesian tsunami in 2004 were reported. These findings revealed that forensic equipment was limited, and there was a lack of or non-existing body bags to store corpses. Moreover, refrigeration for preserving bodies was not available, thus victims were wrapped using their own clothes, and there was a need to quickly identify the bodies due to religious beliefs.

During Hurricane Katrina, more than 1300 deaths were reported [14]. In a report describing the situations faced by a community hospital in the Mississippi Gulf Coast during the hurricane, Babar and colleagues [15] pointed out that the hospital suffered significant damage in the surrounding area. Although the hospital had an effective emergency plan, it faced serious and unforeseen challenges at the time of the event. This particular disaster highlighted several challenges, such as the shortage of personnel to provide services, the inability of rescue personnel to enter the area, the lack of internal and external communication, the lack of appropriate supplies and fuel reserves, and the dramatic reduction of resources in the emergency room, and although, the hospital had power generators, these could not supply the energy demand that was needed. To further complicate the situation, the hospital did not have enough space for the storage of dead bodies. Right after the hurricane, the hospital experienced a sudden increase in the number of dead bodies that were brought in by relatives. This, in turn, caused the hospital to exceed the morgue's capacity, which led to the borrowing of a refrigeration truck from a local company to supply the storage for the dead bodies arriving at the hospital. The 2010 Haiti earthquake led to 222,750 deaths and over 300,000 injuries. Approximately 1.5 million people were left homeless, and more than 3 million persons were affected. The earthquake left a devastated city, a collapsed hospital, and a recovery process with a cost of more than $\$ 4$ billion $[16,17]$.

Disasters such as the Great East-Japan earthquake and tsunami caused almost 16,131 deaths [18], and seriously affected a nuclear power plant, which added an addi- tional threat to the disaster [19]. This disaster is considered to have had one of the worst impacts on the medical system. It destroyed hospitals and clinics in the coastal area leaving the public health system severely damaged and functioning inadequately in the affected areas [18, 19]. In addition to the deaths and missing people in Japan, the tsunami had an impact all over the Pacific Ocean causing additional deaths in Indonesia and California [20]. Although the death toll was lower than in other disasters in other areas, unnecessary death and casualties must be prevented through early interventions in evacuation on primary healthcare centers, rapid search and rescue, and collaborative agreements between agencies. When a healthcare facility suffers the impact of major disasters, to the extent where extensive damage is generated, it cannot continue to offer services and significantly increase the number of mass casualties and fatalities that hospitals can manage on a regular basis. Attempts to understand hospital preparedness for mass fatalities are necessary in order to design contextually culturally and appropriate interventions, prevention efforts and plans that address the possible challenges that hospitals might face. The present study also provided an opportunity to enhance our understanding of the hospitals' preparedness for mass fatality.

\section{Methods}

\subsection{Sample and Procedures}

This study used data from a descriptive survey of hospital emergency rooms in 2011, to assess their level of preparedness and response to an event or disaster that produces mass casualties. The selection of the hospital emergency rooms that participated in the study were obtained from a list of hospitals provided by the Puerto Rico Department of Health Office of Public Health Preparedness and Response (OPHPR). The list consisted of 49 hospitals grouped into six coalitions.

These coalitions emerged as an initiative to create collaborative arrangements between healthcare facilities in Puerto Rico and the OPHPR to improve disaster preparedness. The coalition groups were clustered by regional location as follows: North, South, East, West and Metro, which was divided into Metro A and Metro B. Although 49 hospitals constituted the coalition's first phase, only 44 of these institutions had emergency departments. The distribution of the facilities was: forty-one (41) hospitals and, three (3) community health centers, such as Diagnostic and Treatment Center (DTC) or Family Health Centers, Primary Health Centers or Federally Qualified Health Centers (FQHC's) (330). All these healthcare facilities were located in 23 municipalities throughout Puerto Rico. A total of 39 hospital facilities agreed to participate in the study, yielding a response rate of 
$88.6 \%$.

Given the complex managerial structure of healthcare facilities, it was determined that several hospital personnel would be interviewed, given that it was deemed highly unlikely that a single staff person within the institution would know all the information required and be able to respond to all questions. Therefore, the staff persons contacted to answer the questionnaires were: the hospital administrator; hospital medical director; emergency department director; the Emergency Plan Committee chairperson; the Human Resources Department director; the laboratory director; the epidemiologist or nurse-epidemiologist; the security officer; and the engineer.

A computerized interview modality (computer assisted personal interview, CAPI) was used for data gathering [21]. Trained interviewers conducted the computerized personal interviews. Seven (7) electronic instruments, using CAPI, were constructed considering ten (10) dimensions identified through the scientific literature. These dimensions were: 1) general hospital characteristics; 2) emergency plans; 3) collaborative agreements between agencies; 4) infrastructure and equipment; 5) epidemiologic surveillance; 6) protocols for medical treatment; 7) laboratory; 8) personnel training; 9) communications; and, 10) hospital security. This study was reviewed and approved by the University of Puerto Rico Medical Sciences Campus Institutional Review Board.

\subsection{Measures}

In order to obtain the required information, several questions were asked regarding the morgue's capacity, quantity of body bags available, and the existence of collaborative agreements for the handling of bodies in the healthcare facility. The questions included were the following:

1) Does this healthcare facility have a morgue?

2) What is the storage capacity of the morgue?

3) Can this healthcare facility increase its morgue's capacity? If so, by how much?

4) Does this healthcare facility have body bags to manage a large number of corpses produced by a mass fatality event? If so, how many bags?

5) What type of agreements does this healthcare facility have with other mortuary services in case of a mass fatality event?

6) How does the healthcare facility deal with mass mortality event in their emergency plan?

7) Describe any limitation that this healthcare facility may have to deal with during a mass casualty or fatality event.

\subsection{Statistical Analysis}

All data management and statistical analyses were per- formed using the Statistical Analysis System [22]. Frequencies and univariate analyses were carried out to describe the overall characteristics of the sample population.

\section{Results}

Findings of the study showed limitations in terms of the availability of space and storage capacity of the healthcare facilities' morgues. Regarding the mortuary area (Figure 1) more than three-fourths, constituting 79.5\% (n $=31$ ) of the healthcare facilities, reported having a morgue, while $20.5 \%(n=8)$ reported not having one.

Additional questions about the characteristics of the morgues were also asked of the healthcare facilities that stated that they had a morgue (Table 1). Related to the storage capacity of the morgue among healthcare facilities, almost three-fourths $(74.2 \%, \mathrm{n}=23)$ informed that its morgue can only store three to four corpses in the morgue, while $25.8 \%(\mathrm{n}=8)$ had the capacity for five or more corpses. The maximum average current capacity of the morgues among healthcare facilities was three to four corpses, with a range varying from one to twenty cadavers. About the capacity to increase the healthcare facility's morgue, more than two-thirds $(66.7 \%, n=18)$ of the healthcare facilities indicated the lack of resources to increase their capacity. Only nine (33.3\%) can increase the capacity from four to seven additional corpses. All participants indicated that although their morgue's capacity was limited, they did not need additional space, because external mortuary services were used to collect the corpses. Results related to the current availability of body bags to manage a large number of corpses produced by a mass fatality event in the healthcare facility showed that sixteen (16) facilities (57.1\%) indicated they had no body bags at all, while 12 facilities (42.9\%) indicated to have body bags. Of those that reported having body bags, only nine healthcare facilities indicated the number of available body bags. The average number of bags was 45 , and these ranged from a minimum of one bag to a maximum of 90 bags.

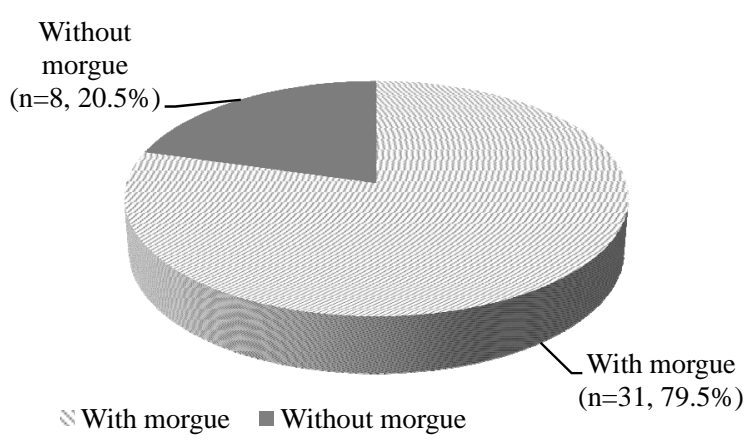

Figure 1. Distribution of participant healthcare facilities with a morgue. 
Table 1. Characteristics of healthcare facilities' morgues.

\begin{tabular}{lcc}
\hline Characteristics of morgues & $\mathbf{n}$ & $\mathbf{\%}$ \\
\hline Morgue capacity & $(23)$ & 74.2 \\
1 to 4 corpses & $(8)$ & 25.8 \\
$\quad 5$ corpses or more & \\
Capacity to increase morgue space* & $(18)$ \\
$\quad$ No & $(9)$ & 33.3 \\
Yes & & \\
Availability of body bags ${ }^{\dagger}$ & $(16)$ & 57.1 \\
No & $(12)$ & 42.9 \\
\hline
\end{tabular}

*Four healthcare facilities could not specify their capacity to increase their morgue. ${ }^{\dagger}$ Only 28 healthcare facilities answered this question.

Questions about the type of agreements with other mortuary services for the disposal of bodies in case of a disaster were asked to healthcare facilities without morgues (Table 2). More than half $(n=5)$ of the healthcare facilities without morgues reported they did not have any agreement with mortuary services for the disposal of bodies in case of a disaster, while one facility reported to have a verbal agreement, and two reported to have a written agreement to address this need. Although this question was not examined among the healthcare facilities that reported having a morgue, all indicated the lack of an agreement with mortuary services in order to transport corpses in case of a major disaster.

Information about how the healthcare facility includes in their emergency plan situations related to patient death information and body handling in mass mortality situations caused by a disaster event were also assessed (Table 3). More than half $(59.5 \%, \mathrm{n}=22)$ reported that their emergency plan includes a protocol to release information about deceased patients to other health facilities in the nearest municipalities; $81.1 \%(\mathrm{n}=30)$ include in their plan the release of information about deceased patients to other health organizations, the municipality, the Puerto Rico Department of Health, police, etc. More than three-thirds $(67.6 \%, \mathrm{n}=25)$ reported including the management of situations related to mass mortality in their emergency plan.

Healthcare facilities reported several limitations in dealing with a mass casualty or fatality event. These topics were assessed as open-ended questions. The common response was related to not having enough experience dealing with mass fatalities or mass casualties. Although participants indicated that their healthcare facility is prepared with specialized resources and committed staff, the lack of a mass fatality and casualties plan and the lack of trainings may prevent an adequate response in case of a
Table 2. Agreements with other mortuary services for the disposal of bodies in case of a disaster.

\begin{tabular}{llc}
\hline Characteristics of morgues & n & $\%$ \\
\hline $\begin{array}{l}\text { Agreements with mortuary } \\
\text { services-facilities with no morgue }{ }^{\ddagger}\end{array}$ & & \\
$\quad$ No agreements & (5) & 62.5 \\
Verbal agreements & (1) & 12.5 \\
$\quad$ Written agreements & (2) & 25.0 \\
\hline${ }^{\ddagger}$ Question asked for healthcare facilities without morgue. & &
\end{tabular}

Table 3. Healthcare facility emergency plans for the release of information on deceased patients and body handling in mass mortality situations.

\begin{tabular}{lcc}
\hline Emergency plan includes: & Yes & \% \\
\hline $\begin{array}{l}\text { "Release of information about deceased patients to } \\
\text { other health facilities in the nearest municipalities }\end{array}$ & 22 & 59.5 \\
$\begin{array}{l}\text { *Release of information about deceased patients to } \\
\text { other health organizations, the municipality, the } \\
\text { health department, police, etc. }\end{array}$ & 30 & 81.1 \\
${ }^{*}$ Managing situations with mass mortality & 25 & 67.6 \\
\hline
\end{tabular}

*Only 37 healthcare facilities answered each question. Two reported they did not know if situations dealing with mass fatality are included in their emergency plan.

disaster. In addition, most healthcare facilities perceived communication barriers between the governmental agencies and hospitals during a major incident. Another concern of healthcare facilities was related to the daily surge, because these are at maximum capacity most of the time, and in the case of a major disaster they will be limited in offering healthcare services, unless there is immediate external help.

\section{Discussion}

Most of the healthcare facilities have morgues, although there are limitations with the current capacity and the lack of resources to increase their capacity in case of a disaster. In addition, all healthcare facilities rely on external mortuary services to collect the corpses on a daily basis. Moreover, two-thirds of the healthcare facilities without morgues do not have casual agreements or any informal agreement with mortuary services for the disposal of bodies in case of a major disaster, a similar situation that occurs among those which reported having a morgue. In most healthcare facilities, morgues are limited in space and cannot increase their capacity. This situation is mostly associated with the hospital's budget being assigned to other priority areas. Moreover, the maintenance of a morgue requires dedicated personnel and materials for the preservation of corpses, which will require a budget allocation. 
Disasters can strike at any moment causing a saturation of the systems and affecting the response. Healthcare facilities are complex institutions and their resources are limited [23,24]. Therefore, it is extremely important to strengthen hospital preparedness for mass fatalities. Efforts dedicated to preparedness would help in prevention, intervention and planning processes and dealing with corpses using appropriate guidelines in case of a major disaster [18,19].

The availability of body bags among nine healthcare facilities was limited, with an average of 45 body bags, ranging between one to ninety bags. A study conducted by Sahelangi and Novita [13], demonstrated several situations and challenges that occurred after the Indonesian Tsunami. This study assessed the speed with which resources became scarce, time it took for hospitals to become overwhelmed, loss of hospital personnel, lack of body bags for the amount of corpses and the challenge that the weather conditions created, given that it accelerated the decomposition of bodies, making it impossible to identify them.

Puerto Rico has experienced several situations involving mass fatalities. The case of Mameyes on October 7, 1985 was associated with torrential rains, affecting the Mameyes neighborhood disappeared under an avalanche of mud. This mudslide caused the destruction of more than 100 homes and 129 deaths. Many bodies were never recovered or identified. As a result of this incident the government approved Law No. 1 on December 12, 1985 (Act Declaring Deaths in Cases of Catastrophic Events) [25,26]. Healthcare facilities from our study reported dealing with the Mameyes disaster, and their morgue exceeded its capacity, which led them to rent a refrigerated truck to place bodies and human remains. A year later, another incident with mass fatalities occurred on December 31, 1986, a fire caused by a union worker at the Dupont Plaza Hotel, left 97 dead and 140 wounded, most of them tourists [25]. Another mass fatalities incident occurred on November 21, 1996, when a gas line explosion ripped through the Humberto Vidal building in Río Piedras, injuring 85 people and killing 30. The bodies of the dead were lined and covered with sheets in the chapel of La Milagrosa Catholic School, located opposite the site of the explosion [27].

A disaster event may cause the death of hundreds of thousands of people, and the handling and disposal of dead bodies is one of the most difficult aspects in the response process [28]. Inappropriate management might result in distress to families and communities, and may divert attention from other situations with equal priority, such as healthcare services or reducing the capacity of disaster response personnel to rescue survivors [1,29].

Although more than half of the healthcare facilities that participated in this study include in their plans areas related to the release of information about deceased patients to health organizations, the health department, the municipality, and the police department among others, there is no specific plan for dealing with mass fatalities. The healthcare facilities that participated in this study had limited space for storage, and the need of training in the areas of mass casualties and mass fatalities. The development of specific plans for handling mass mortality is important to help mitigate the effect that may occur in case of a major disaster. Healthcare facilities' mass fatality plans require systematic documentation regarding the handling of corpses and the dissemination of information regarding dead and missing persons [28,29].

Developing mass fatalities plans for healthcare facilities requires not only support from the board of directors of these institutions, but the need to establish collaborative agreements allowing the development of preparedness measures and coordinated planning in conjunction with various agencies. In addition, mass fatalities plans should include protocols that deal with identifying the best methods of refrigeration, conservation, recovery and storage of bodies, identification of corpses through methods such as fingerprinting, dental records, DNA records, photographs, identification records, as well as include how corpses will be delivered to their families $[11,12,28]$. Additionally, plans for mass fatalities should be integrated into the legal system of the country where the disaster occurs, but at the same time these must show sensitivity to the customs of the victims affected and consider the religious, ethnic, cultural aspects, and support mechanisms for surviving family members and responders [11,12,28].

Although some legal aspects are addressed in Puerto Rico, this is not enough to deal with mass mortalities. It is extremely important to develop a national plan, in conjunction with all stakeholders in government agencies and hospitals, to create a nationwide mass mortality plan that can meet the crisis standards of care that must be followed in the event of a major disaster.

\section{Acknowledgements}

Data for this study came from the Assessment of the Emergency and Disaster Preparedness and Response Capabilities of Hospital Emergency Rooms in Puerto Rico, conducted during 2011. Funding was provided by ASPR-USDHHS, administered by the Puerto Rico Department of Health, Office for Public Health Preparedness and Response under contract 2010-DS0609. We acknowledge the support we received from the hospitals that participated in the study and are grateful for the collaboration of the Hospital Association of Puerto Rico and for their willingness to take into account data derived from our studies in formulating health policy. We would 
like to thank Julieanne Miranda Bermúdez, Wined Ramírez López and, Luisa M. Ortíz Labiosa for helping in the edition of this manuscript. The authors also thank Ana María Mercado Casillas, Yarí Valle-Moro for their help during the survey.

\section{REFERENCES}

[1] WHO-World Health Organization, "Mass Casualty Management Systems: Strategies and Guidelines for Building Health Sector Capacity,” Health Action in Crises Injuries and Violence Prevention, WHO Publications, Geneva, 2007, p. 38.

[2] M. Matzo, T. Powell, J. Surbeck and C. Erickson-Hurt, "Palliative Care Considerations in Mass Casualty Events with Scarce Resources," Biosecurity and Bioterrorism: Biodefense Strategy, Practice, and Science, Vol. 7, No. 2, 2009.

[3] L. A. Levy, et al., "Interdisciplinary Approach to AllHazards Preparedness: Are You Ready? How Do We Know?” Journal of Public Health Management Practice, Vol. 15, No. 2, 2009, pp. S8-S12. http://dx.doi.org/10.1097/01.PHH.0000345979.67724.80

[4] C. Perera, "After the Tsunami: Legal Implications of Mass Burials of Unidentified Victims in Sri Lanka," PLoS Medicine, Vol. 2, No. 6, 2005, pp. 185-187. http://dx.doi.org/10.1371/journal.pmed.0020185

[5] S. Doocy, et al., "Tsunami Mortality in Aceh Province, Indonesia," Bulletin of the World Health Organization, Vol. 85, 2007, pp. 273-278. http://dx.doi.org/10.2471/BLT.06.033308

[6] C. K. Brands, et al., "Complete Self-Sufficiency Planning: Designing and Building Disaster-Ready Hospitals," Southern Medical Journal, Vol. 106, 2013.

[7] R. W. Niska and C. W. Burt, "Bioterrorism and Mass Casualty Preparedness in Hospitals: United States, 2003,” Advance Data from Vital and Health Statistics, No. 364, National Center for Health Statistics, Hyattsville, 2005, p. 15.

[8] R. W. Niska and I. M. Shimizu, "Hospital Preparedness for Emergency Response: United States, 2008,” N.S. Report, US Department of Human and Health Services, Bethesda, 2011.

[9] R. M. Walk, T. F. Donahue, R. P. Sharpe and S. D. Safford, "Three Phases of Disaster Relief in Haiti-Pediatric Surgical Care on Board the United States Naval Ship Comfort,” Journal of Pediatric Surgery, Vol. 46, No. 10, 2011, pp. 1978-1984.

http://dx.doi.org/10.1016/j.jpedsurg.2011.04.014

[10] S. M. Watkins, et al, "State-Level Emergency Preparedness and Response Capabilities," Disaster Medicine and Public Health Preparedness, Vol. 5, Suppl. S1, 2011, pp. S134-S142. http://dx.doi.org/10.1001/dmp.2011.26

[11] O. Morgan and C. de Ville de Goyet, "Dispelling Disaster Myths about Dead Bodies and Disease: The Role of Scientific Evidence and the Media," Revista Panamericana de Salud Pública, Vol. 18, No. 1, 2005, pp. 33-36. http://dx.doi.org/10.1590/S1020-49892005000600006
[12] O. Morgan, P. Sribanditmongkol, C. Perera, Y. Sulasmi, D. Van Alphen and E. Sondorp, "Mass Fatality Management Following the South Asian Tsunami Sisaster: Case studies in Thailand, Indonesia, and Sri Lanka," PLoS medicine, Vol. 3, No. 6, 2006, pp. 809-815. http://dx.doi.org/10.1371/journal.pmed.0030195

[13] P. Sahelangi and M. Novita, "Role of Dentists in Indonesian Disaster Victim Identification Operations: Religious \& Cultural Aspects," Journal of Forensic Odontostomatology, Vol. 30, No. 1, 2012, p. 11.

[14] CDC Center for Disease Control and Prevention, "The State of CDC, FISCAL YEAR 2005,” US Department of Human Health Services, 2005.

[15] I. Babar and R. Rinker, "Direct Patient Care during an Acute Disaster: Chasing the Will-o'-the-Wisp,” Critical Care, Vol. 10, No. 1, 2006, p. 206. http://dx.doi.org/10.1186/cc3943

[16] A. Bhattacharjee and R. Lossio, "Evaluation of OCHA Response to the Haiti Earthquake,” Final Report, 2011. p. 118.

[17] S. Doocy, M. Cherewick and T. Kirsch, "Mortality Following the Haitian Earthquake of 2010: A Stratified Cluster Survey,” Population Health Metrics, Vol. 11, No. 5, 2013.

[18] A. Fuse and H. Yokota, "Lessons Learned from the Japan Earthquake and Tsunami, 2011,” Journal of Nippon Medical School, Vol. 79, No. 4, 2012, pp. 312-315. http://dx.doi.org/10.1272/jnms.79.312

[19] A. Ishigaki, H. Hogashi, T. Sakamoto and S. Shibahara, "The Great East-Japan Earthquake and Devastating Tsunami: An Update and Lessons from the Past Great Earthquakes in Japan since 1923,” Tohoku Journal of Experimental Medicine, Vol. 229, No. 4, 2013, pp. 287-299. http://dx.doi.org/10.1620/tjem.229.287

[20] P. Dunbar, H. McCullough, G. Mungov, J. Varner and K. Stroker, "Tohoku Earthquake and Tsunami Data Available from the National Oceanic and Atmospheric Administration/National Geophysical Data Center. Geomatics,” Natural Hazards \& Risk, Vol. 2, No. 4, 2011, pp. 305-323. http://dx.doi.org/10.1080/19475705.2011.632443

[21] NOVA Research Company, QDSTM, "Questionnaire Development System,” Bethesda, 2010.

[22] SAS Institute Inc., "Base SAS ${ }^{\circledR} 9.3$ Procedures Guide B.S.P. Guide,” Cary, 2011.

[23] B. Adini, A. Goldberg, D. Laor, R. Cohen, R. Zadok and Y. Bar-Dayan, "Factors That May Influence the Preparation of Standards of Procedures for Dealing with MassCasualty Incidents,” Prehospital and Disaster Medicine, Vol. 22, No. 3, 2007, pp. 175-180.

[24] B. Adini, A. Goldberg, D. Laor, R. Cohen, R. Zadok and Y. Bar-Dayan, “Assessing Levels of Hospital Emergency Preparedness,” Prehospital and Disaster Medicine, Vol. 21, No. 6, 2006, pp. 451-457.

[25] E. K. Noji, "The Public Health Consequences of Disasters,” Oxford University Press, New York, 1997.

[26] Commonwealth of Puerto Rico, "Ley Para Declarar la Muerte en Casos de Eventos Catastróficos,” Ley Núm 1 
del 12 de Diciembre de 1985.

http://www.lexjuris.com/LEXMATE/salud/lexmuertes.htm

[27] FEMA, “Humberto Vidal Building Explosion,” 1996.

http://www.fema.gov/humberto-vidal-building-explosion1996

[28] O. Morgan and M. Tidball-Binz, "Management of Dead
Bodies after Disasters: A Field Manual for First Responders,” Panamerican Health Organization, 2009.

[29] World Health Organization, "Hospital Emergency Response Checklist: An All-Hazards Tool for Hospital Administrators and Emergency Managers,” WHO, Regional Office for Europe, Copenhagen, 2011. 